\title{
CETAF Collection Dashboard: Mapping natural history collections diversity
}

\author{
Patrick Semal ${ }^{\ddagger}$, Marielle Adam ${ }^{\ddagger}$, Didier Van den Spiegel ${ }^{\S}$, Franck Theeten§, Henry Engledowl,

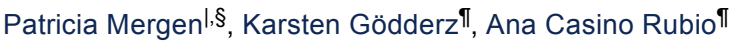 \\ ‡ Royal Belgian Institute of Natural Sciences (RBINS), Brussels, Belgium \\ § Royal Museum for Central Africa (RMCA), Tervuren, Belgium \\ | Meise Botanic Garden (MBG), Meise, Belgium \\ I Consortium of European Taxonomic Facilities (CETAF, AISBL), Brussels, Belgium
}

Corresponding author: Patrick Semal (patrick.semal@naturalsciences.be)

Received: 03 Sep 2019 | Published: 17 Sep 2019

Citation: Semal P, Adam M, Van den Spiegel D, Theeten F, Engledow H, Mergen P, Gödderz K, Rubio AC (2019)

CETAF Collection Dashboard: Mapping natural history collections diversity. Biodiversity Information Science and Standards 3: e39667. https://doi.org/10.3897/biss.3.39667

\begin{abstract}
Several initiatives aim to map the diversity of Natural History (NH) collections and standardise their descriptions. The Global Registry of Biodiversity Repositories (GRBio) is the most recent global registry. Unfortunately the server has been down since mid-2018 but the Global Biodiversity Information Facility (GBIF) recently "rescued" this data. In addition to this, the One World Collection exercise is a set of high-level collection descriptors (size, group coverage and geographic distribution) supporting a common strategy between the largest world institutions. Despite these efforts, a large part of the $\mathrm{NH}$ collections remains digitally unavailable and digitisation at the specimen level will take several decades.

A new $\mathrm{NH}$ collections dashboard is needed in order to harmonise the efforts of the institutions. The Consortium of European Taxonomic Facilities (CETAF) is a good place to introduce this excercise. CETAF's members hold over half of the world's NH collections, representing $80 \%$ of the world's bio- and geo-diversity. Most of these collections are now engaged in the preparation for the common process of the Distributed System of Scientific Collections (DiSSCo, European Strategy Forum on Research Infrastructure).
\end{abstract}


Additionally in Belgium, the Royal Belgian Institute of Natural Sciences (RBINS), Royal Museum of Central Africa (RMCA), Meise Botanic Garden ( $\underline{\mathrm{MBG}}$ ) and CETAF have joined efforts to set up a common research portal (Natural Heritage, BRAIN-be project). The goal is to link together several collection management systems (CMS) and to (re)create links between isolated collection items.

The CETAF collections dashboard splits the information into small metadata units related to topics relevant to the collections (taxonomy, geographic distribution, digitisation strategy and coverage, stratigraphy, etc.). The model allows for the creation of new units without a complete modification of the database structure. All units are defined by the Dublin Core and by fields derived from the Innovation and consolidation for large scale digitisation of natural heritage (ICEDIG) d2.3 deliverable (van Egmond et al. 2019).

The object hierarchy allows for the creation of sub-collections and preserves the unity of the information. The CMS has an internal object database with a full index and a faceted search interface. It also has web services and XLS (Microsoft $\circledast$ Excel ${ }^{\circledR}$ ) import/export functionalities. The collection dashboard also includes a complete workflow and access rights management at the object level. This is important for the information that is protected by the EU General Data Protection Regulation (GDPR). The dashboard is now being evaluated with the collections hosted by the partners of Natural Heritage. The system will be proposed to CETAF members and connections will be established with the international portals such as the GBIF or the future DiSSCo portal.

\section{Keywords}

natural history collections, DiSSCo, collections indicators, digitisation, open source, webservices

\section{Presenting author}

Patrick Semal

\section{Presented at}

Biodiversity_Next 2019

\section{Funding program}

BRAIN-be Belgian Research Action through Interdisciplinary Networks 


\section{Grant title}

NaturalHeritage: BR/175/A3/NATURALHERITAGE

\section{Hosting institution}

Royal Belgian Institute of Natural Sciences (RBINS)

Consortium of European Taxonomic Facilities (CETAF)

29 rue Vautier, B-1000 Brussels, Belgium

\section{References}

- van Egmond E, Willemse L, Paul D, Woodburn M, Casino A, Gödderz K, Vermeersch X, Bloothoofd J, Wijers A, Raes N (2019) Design of a Collection Digitisation Dashboard.

Zenodo https://doi.org/10.5281/ZENODO.2621055 